\title{
TYPE II DIABETICS; FREQUENCY OF DIABETIC KETOACIDOSIS
}

1. Associate Professor Medicine Sahiwal Medical College, Sahiwal 2. Assistant Professor Medicine Sahiwal Medical College, Sahiwal Assistant Professor Medicine Sahiwal Medical College, Sahiwal

Correspondence Address: Dr. Azfar Farogh

Associate Professor Medicine Sahiwal Medical College, Sahiwal Drazfarfarogh1@gmail.com

\section{Article received on:} 10/10/2015

Accepted for publication: 14/11/2015

Received after proof reading: 09/02/2016

\section{Dr. Azfar Farogh', Dr. Muhammad Arif Mahmood ${ }^{2}$, Dr. Khalil Ahmad ${ }^{3}$}

\begin{abstract}
Objectives: To determine the frequency of diabetic ketoacidosis in type II diabetic patients. Study Design: Cross sectional study. Setting: Department of Medicine, Sahiwal Medical College Sahiwal. Period: September 2014 to March 2015. Material and method: Permission was taken from Institutional review board and written informed consent was taken from every patient. Total 189 patients with type II DM (Un-controlled) having Fasting plasma glucose level $\geq 126 \mathrm{mg} / \mathrm{dl}$ either male or female having age 35 years to 65 years were included in the study. Results: Total 189 patients with type II diabetes mellitus were included in this study. Mean age of the $50.09 \pm 9.39$ years. Male patients were $79(42 \%)$ and female patients were $110(58 \%)$. Insignificant association between gander and Ketoacidosis was seen. No association of family history of diabetes mellitus with Ketoacidosis was found. Conclusion: Results of this study showed that male or female can be equally victim of diabetic ketoacidosis. Diabetic ketoacidosis can be develop equally in younger or older age group. No significant difference for the development of diabetic ketoacidosis was found between obese/non-obese and patients with family history of diabetes or without family history of diabetes.
\end{abstract}

Key words: Diabetes mellitus, diabetic ketoacidosis, fasting plasma glucose, random plasma glucose.

Article Citation: Farogh A, Mahmood MA, Ahmad K. Type II diabetics; frequency of diabetic ketoacidosis. Professional Med J 2016;23(2):133-137. DOI: 10.17957/ TPMJ/16.3122

\section{INTRODUCTION}

Diabetes mellitus (DM) is a syndrome with disordered metabolism and inappropriate hyperglycemia because of reduction in secretion of insulin or with combination of insulin resistance and insufficient insulin secretion to compensate. ${ }^{1}$ In year 2000 the prevalence of DM was $2.8 \%$ and it will be reached to $4.4 \%$ by the year $2030 .^{2}$

According to some small scale studies which were conducted in different areas of Pakistan, the prevalence of DM was 5.3\% but exact prevalence of DM is not available in literature. ${ }^{3}$

From last two decades the prevalence of DM has increased dramatically. It is supposed that the number of diabetics will grow from 135 million to 300 million by the year 2025 globally. Unluckily the main increase will take place in under develop countries and in Pakistani population, the number of patients with DM is estimated to be doubled by the year 2025. In Pakistan about eight million people have DM and almost the same number is suffering from impaired glucose tolerance. ${ }^{4}$

Diabetic ketoacidosis (DKA) and hyperosmolar non ketotic coma are the most common acute complications of DM. ${ }^{5,6}$ DKA is a life threatening medical emergency and its mortality rate varies from $1-10 \%$ which depends on the experience of treating hospital or medical center. ${ }^{7}$

In present study the frequency of DKA will be determined in type II diabetic patients presenting at Medical Departments of DHQ Teaching Hospital, Sahiwal.

In Pakistan, the frequency of diabetic ketoacidosis in patients with diabetes mellitus has not been much studied. The results of this will provide us the local data regarding DKA and will also be helpful to improve medical care of the patients and will decrease morbidity and mortality of patients presenting with DKA. 


\section{MATERIAL AND METHOD}

This study was conducted at Department of Medicine, Sahiwal Medical College Sahiwal from September 2014 to March 2015. Permission was taken from Institutional review committee and written informed consent was taken from every patient. Total 189 patients with type II DM (Uncontrolled) having Fasting plasma glucose level $\geq 126 \mathrm{mg} /$ dl either male or female having age 35 years to 65 years were enrolled in this study. Patients with random plasma glucose $>600 \mathrm{mg} /$ $\mathrm{dL}$, serum osmolality $>310 \mathrm{mosm} / \mathrm{kg}$, patients with hepatic uremic encephalopathy and patients with stroke were excluded from the study.

Weight and height was measured of all patients for BMI. Family history of diabetes mellitus was also recorded in pre-designed proforma. Random sample of $5 \mathrm{ml}$ blood was drawn and send to the laboratory for investigations like glucose, blood $\mathrm{pH}$ and Serum bicarbonate. Fasting urine sample was also be taken for ketones. Demographic data like age and gender was also entered in predesigned Performa.

Data was entered on computer software SPSS version 16. Mean $\pm S D$ was calculated for age as quantitative variable. Frequencies and percentages were done for ketoacidosis, gender, obesity and family history of diabetes mellitus as categorical variables. Stratification was done for age, gender, obesity and family history of diabetes mellitus to control the effect modifiers. Chi-square test was applied and p-value $\leq 5 \%$ was considered as statistically significant.

\section{RESULTS}

Total 189 patients with DM-II were included in this study. Mean age of the $50.09 \pm 9.39$ years. Out of 189 patients male patients were $79(42 \%)$ and female patients were 110 (58\%). (Fig. 1)

Among the 189 patients, 120 (63\%) patients were with family history of diabetes mellitus and $69(37 \%)$ patients was without family history of diabetes mellitus. (Fig. 2). As shown in fig. 3 , obese were 119 (635) and non-obese were 70 (375). Ketoacidosis was found in 47 (25\%) patients. (Fig.4)

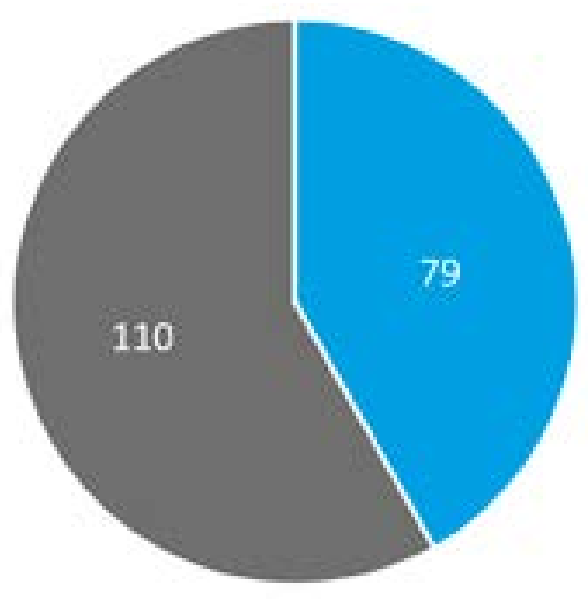

- Male $=$ Female

Fig-1. Frequency for gender

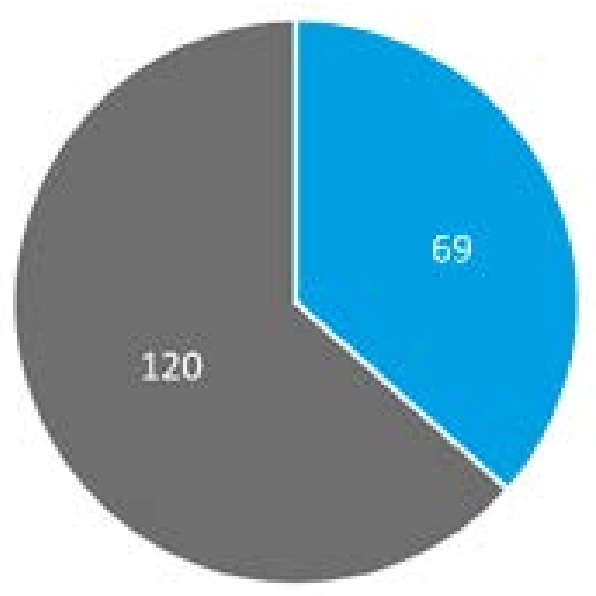

No $=$ Yes

Fig-2. Frequencies for family history of diabetes mellitus

Patients were divided into two age groups, age group 35-50 years and age group 51-65 years. Age group 35-50 years consisted on 105 (55.56\%) patients and Ketoacidosis was found in 27 (25.71\%) patients. Among the 84 (44.44\%) patients of age group 51-65 years, Ketoacidosis was found in 20 (11.9\%) patients. Insignificant association was found between age and Ketoacidosis. P. value 0.865. (Table I) Stratification in relation to gender was done. Out of $79(41.8 \%)$ male patients Ketoacidosis was 
found in 21 (26.58\%) patients. Among the 110 $(58.2 \%)$ female patients, Ketoacidosis was found in $26(23.64 \%)$ patients. Insignificant association between gander and Ketoacidosis was seen. P-value 0.733. (Table II)

Total 120 (63.49\%) were present family history of

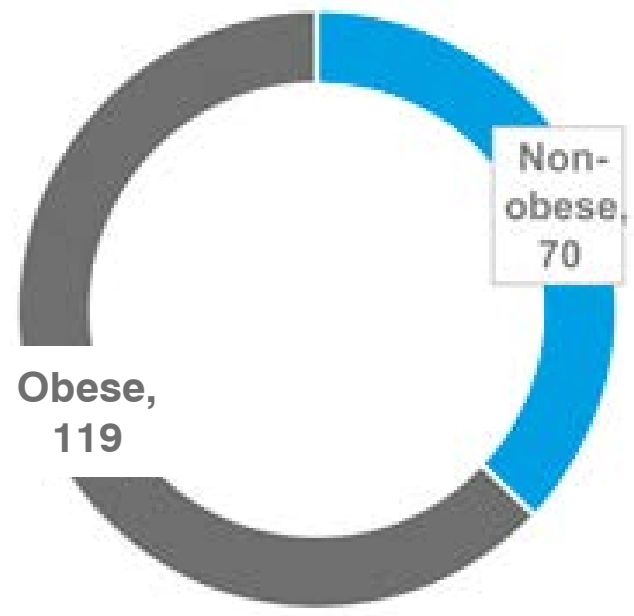

- Non-obese = Obese

Fig-3. Frequency for obesity diabetes mellitus and Ketoacidosis was seen in $31(25.83 \%)$ patients. Out of $69(36.51 \%)$ patients without family history of diabetes mellitus, Ketoacidosis was seen in 16 (23.19\%) patients. No association of family history of diabetes mellitus with Ketoacidosis was found. P. value 0.730. (Table III)

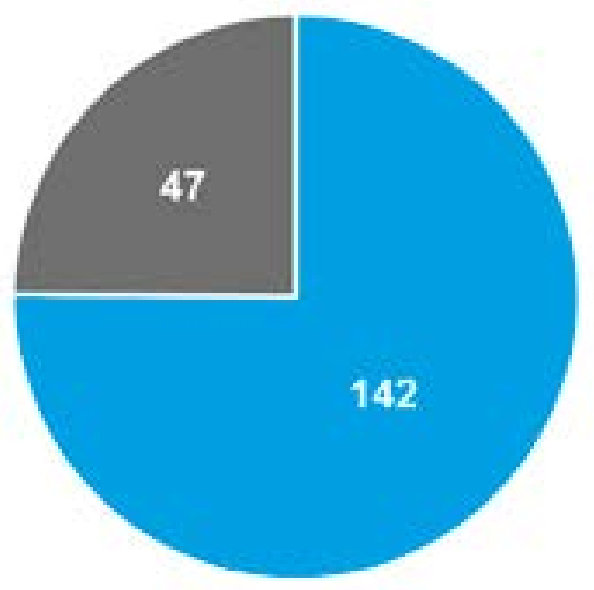

$\square$ No $=$ Yes

Fig-4. Frequency for Ketoacidosis

\begin{tabular}{|c|c|c|c|c|}
\hline \multirow{2}{*}{ Age Group } & \multicolumn{2}{|c|}{ Ketoacidosis } & Total & P. value \\
\hline $35-50$ & Yes (\%) & No (\%) & \multirow{2}{*}{$\mathbf{0 . 8 6 5}$} \\
\hline $51-65$ & $27(25.71)$ & $78(74.29)$ & $105(55.56)$ & \\
\hline Total & $20(11.9)$ & $64(76.1)$ & $84(44.44)$ & 189 \\
\hline
\end{tabular}

\begin{tabular}{|c|c|c|c|c|}
\hline \multirow{2}{*}{ Gender } & \multicolumn{2}{|c|}{ Ketoacidosis } & Total & P. value \\
\hline Male & Yes (\%) & No (\%) & (\%) \\
\hline Female & $21(\mathbf{2 6 . 5 8 )}$ & $58(73.42)$ & $110(58.2)$ & $\mathbf{0 . 7 3 3}$ \\
\hline Total & $26(23.64)$ & $84(76.36)$ & $\mathbf{1 8 9}$ \\
\hline
\end{tabular}

\begin{tabular}{|c|c|c|c|c|}
\hline \multirow{2}{*}{ Family History } & \multicolumn{2}{|c|}{ Ketoacidosis } & Total & P. value \\
\hline Yes & $31(\mathbf{2 5 . 8 3 )}$ & $89(\mathbf{7 4 . 1 7 )}$ & $120(63.49)$ & $\mathbf{0 . 7 3 0}$ \\
\hline No & $16(23.19)$ & $53(76.81)$ & $69(36.51)$ & \\
\hline Total & $\mathbf{4 7}(\mathbf{2 4 . 8 7 )}$ & $\mathbf{1 4 2}(\mathbf{7 5 . 1 3 )}$ & $\mathbf{1 8 9}$ \\
\hline & Table-III. Stratification for family history of diabetes mellitus \\
\hline
\end{tabular}




\begin{tabular}{|c|c|c|c|c|}
\hline \multirow{2}{*}{ Obesity } & \multicolumn{2}{|c|}{ Ketoacidosis } & Total & P. value \\
\hline Obese & Yes (\%) & No (\%) & $119(62.96)$ \\
\hline Non-obese & $29(24.37)$ & $90(75.63)$ & $70(37.04)$ \\
\hline Total & $18(25.71)$ & $52(74.29)$ & $\mathbf{1 8 9}$ \\
\hline
\end{tabular}

As shown in table No. IV, out of 119 (62.96\%) obese patients Ketoacidosis was found in 29 (24.37\%) patients. Among the 70 (37.04\%) nonobese patients, Ketoacidosis was seen in 18 $(25.71 \%)$ patients. No relationship between obesity and Ketoacidosis was observed. P. value 0.863 .

\section{DISCUSSION}

Hyperglycemia presents as DKA is the most common presentation in diabetics at emergency. 8 It is fatal if untreated however mortality varies from 5 to 10 percent in different centers. ${ }^{9}$ No age is immune to it but it frequently occur in DM-I of younger age. ${ }^{10}$ Nausea, vomiting, abdominal pain and dehydration in semi-conscious and conscious patients with respiratory distress is the most common clinical presentation. ${ }^{11}$ Biochemical markers are serum glucose $>200 \mathrm{mg} / \mathrm{dl}$ and ketonuria in a clinically suspected diabetics. $^{12}$ Pathophysiology of such state is due to absence of insulin, so tissues of the body do not take up glucose thus counter hormones such as glucagon and catecholamines increase the catabolism of lipid (triglyceride) into free fatty acids and thus increase gluconeogenesis for hyperglycemia. Free fatty acids lead to into ketonemia and ketonuria by beta oxidation. ${ }^{12}$

In our study mean age of the patients with DM-II was $50.09 \pm 9.39$ years, comparable mean age of the patients with DM-II was reported by Sheikh et al. ${ }^{8}$ Mean age of the patients with DM-II reported by Pinto et $\mathrm{al}^{13}$ in their study was $45 \pm 12$ which is also in agreement with our study. In present study male patients was $42 \%$ and female patients were $58 \%$ which is comparable with a study by Sheikh et $\mathrm{al}^{8}{ }^{8}$ in his study male patients were $38.6 \%$ and female patients were $61.4 \%$. Study of Habib is also in agreement with our study, he reported in his study male diabetics $41 \%$ and female diabetics $59 \% .{ }^{14}$
In our study DKA was found in $25 \%$ patients. Ganie et $\mathrm{al}^{15}$ reported DKA in $20 \%$ patients. Findings of their study are comparable with our findings. But Sheikh et al found DKA in $14.3 \%$ patients which is not in agreement with our study. ${ }^{8}$ In another study, a higher proportion (41.7\%) of patients with DKA was reported. ${ }^{16}$ Pitteloud et $a 1^{17}$ reported diabetic ketoacidosis in $16 \%$ patients which is also comparable with our findings.

\section{CONCLUSION}

Results of this study showed that male or female can be equally victim of diabetic ketoacidosis. Diabetic ketoacidosis can be develop equally in younger or older age group. No significant difference for the development of diabetic ketoacidosis was found between obese/nonobese and patients with family history of diabetes or without family history of diabetes.

Copyright(C) 14 Nov, 2015.

\section{REFERENCES}

1. Masharni U. Diabetes mellitus and hypoglycemia. In: Tierney LM, Me Phee SJ, Papadakis MA, editors. Current medical diagnosis and treatment, 50th ed. New York, McGraw-Hill;2011. P.1219-65.

2. Wild S, Roglic G, Green A, Sicree R, King H. Global prevalence of diabetes: estimates for the year 2000 and projections for 2030. Diabetes Care. 2004 May;27(5):1047-53.

3. Jawaid SA, Jafary $\mathrm{MH}$. Training of nurses in diabetes care. Pak J Med Sci 2003; 19:67-9.

4. Tarin SMA, Khan M. Pattern of diabetic admissions in medical ward. Pak J Med Res 2004;43:157-62.

5. Powers AC. Diabetes Mellitus. In: Kasper DL, Fauci AS, Lango D, Braundwald E. Hauser principles of internal medicine. Vol II. 17 SL, James JL, editors. Harrison's ${ }_{\text {th }}$ ed. New York, McGraw-Hill: 2009. P.2152-80.

6. Wolfsdorf J, Craig ME, Daneman D, Dunger D. Diabetic ketoacidosis. Pediatr Diabetes 2007;8:28-42. 
7. Niaz Z, Rallaq A, Chaudhary UJ, Awais M, Yaseen MA, Naseer I, et al. Mortality review of diabetic ketoacidosis in Mayo Hospital, Lahore. Biomedica 2005;21:83-5.

8. Sheikh GA, Dilshad M, Khalid A. Frequency of diabetic ketoacidosis in diabetic patients. 2010 [cited 2014 Mar 25]; Available from: http://jumdc.tuf.edu.pk/articles/ volume-2/no-2/JUMDC-5.pdf

9. Niaz Z, Rallaq A, Chaudhary UJ, Awais M, Yaseen MA, Naseer I, et al. Mortality review of diabetic ketoacidosis in Mayo Hospital, Lahore. Biomedica 2005; 21:83-5.

10. Muir AB, Quisling RG and Yang MC. Cerebral edema in childhood diabetic ketoacidosis: natural history, radiographic findings and early identification. Diabetes Care 2004; 27:1541-6.

11. Lopez Vicente M, Ortega Gutierrz S, Amlie Lefond $C$ and Torbey MT. Diagnosis and management of pediatric arterial ischemic stroke. Journal of stroke and cerebrovascular diseases. 2010; 19:175-83.

12. Sharma V and Hadebe N. Diabetic ketoacidosis: principles of management. $\mathrm{Br} \mathrm{J}$ Hosp Med (Lond) 2007; 68:184-9.

13. Pinto ME, Villena JE and Villena AE. Diabetic ketoacidosis in Peruvian patients with type 2 diabetes mellitus. Endocr Pract 2008; 14:442-6.

14. Habib HS. Frequency and clinical characteristics of ketoacidosis at onset of childhood type 1 diabetes mellitus in Northwest Saudi Arabia. Saudi Med J. 2005 Dec;26(12):1936-9.

15. Ganie MA, Koul S, Razvi HA, Laway BA, Zargar AH. Hyperglycemic emergencies in Indian patients with diabetes mellitus on pilgrimage to Amarnathji yatra. Indian J Endocrinol Metab. 2012 Mar;16 Suppl 1:S8790.

16. Edo AE. Clinical profile and outcomes of adult patients with hyperglycemic emergencies managed at a tertiary care hospital in Nigeria. Niger Med J. 2012 Jul;53(3):121-5.

17. Pitteloud N, Philippe J. Characteristics of Caucasian type 2 diabetic patients during ketoacidosis and at follow-up. Schweiz Med Wochenschr. $2000 \mathrm{Apr}$ 22;130(16):576-82.

\section{PREVIOUS RELATED STUDY}

Mohammad Mohsin Rana, Muhammad Saeed Akhtar, Muhammad Badar bashir, Abaid-ur-Rehman. TYPE 2 DIABETICS COMPONENTS OF THE METABOLIC SYNDROME (Original) Prof Med Jour 13(3) 453-459 Jul, Aug, Sep, 2006.

Mohammad Mohsin Rana, Muhammad Saeed Akhtar, Badar Bashir, Abaid-ur-Rehman. TYPE 2 DIABETICS; THE RELATIONSHIP BETWEEN THE SERUM CHOLESTEROL AND TRIGLYCEROIDS (Original) Prof Med Jour 14(2) 337-343 Apr, May, Jun, 2007.

\begin{tabular}{|c|l|l|l|}
\hline \multicolumn{3}{|c|}{ AUTHORSHIP AND CONTRIBUTION DECLARATION } \\
\hline Sr. \# & \multicolumn{1}{|c|}{ Author-s Full Name } & \multicolumn{1}{|c|}{ Contribution to the paper } & Author=s Signature \\
\hline 1 & Dr. Azfar Farogh & Main Author & \\
\hline 2 & Dr. M. Arif Mahmood & Data collection and analysis & \\
\hline 3 & Dr. Khalil Ahmad & $\begin{array}{l}\text { Searching on internet and } \\
\text { editing }\end{array}$ & Her. \\
\hline
\end{tabular}

